\title{
PATIENT HEALTH MONITORING USING ARDUINO THROUGH IOT
}

\author{
${ }^{1}$ Dr.B.Srikanth \\ ${ }^{\text {I} P r o f e s s o r, ~ D e p t . o f ~ C S E, K a l l a m ~ H a r a n a d h a r e d d y ~ I n s t i t u t e ~ o f ~ T e c h n o l o g y, ~}$ \\ Guntur,AP,India. \\ ${ }^{2}$ P.Divya \\ ${ }^{2,}$ U.G Student, Dept.of CSE,Kallam Haranadhareddy Institute of Technology, \\ Guntur,AP,India. \\ ${ }^{3}$ P.Nandini., \\ ${ }^{3,}$ U.G Student, Dept.of CSE,Kallam Haranadhareddy Institute of Technology, \\ Guntur,AP,India. \\ ${ }^{4}$ Sk.Sabira , \\ 4, U.G Student, Dept.of CSE,Kallam Haranadhareddy Institute of Technology, \\ Guntur,AP,India. \\ 5 T.Bharathi. \\ ${ }^{5}$ U.G Student, Dept.of CSE,Kallam Haranadhareddy Institute of Technology, \\ Guntur,AP,India.
}

Article DOI: $\underline{\text { https://doi.org/10.36713/epra4554 }}$

\begin{abstract}
Health has prime importance in our day-to-day life. Sound health is necessary to do the daily work properly. Monitoring your beloved ones becomes a difficult task in the modern day life. Keeping track of the health status of the patient at home is a difficult task. Especially old age patients should be periodically monitored and their loved ones need to be informed about their health status from time to time while at work. An innovative system that automated this task with ease. System puts forward a smart patient health monitoring system that uses Sensors to track patient health and uses internet to inform their loved ones in case of any issues. This project aims at developing a system which gives body temperature, blood pressure and heart rate using LM35, pressure sensor and pulse sensor respectively. These sensors are interfaced with Micro Controller Arduino ATMEGA328. This MicroController Arduino ATMEGA328 is provided with a programming written in embedded c language. The data is sent to the server through wireless data transmission. This wireless data transmission is done by ESP8266 module. Data is transmitted on IOT platform i.e. thing speak which generates the graphs of Temperature, Blood Pressure and Heart Beat over a period of time. Data visualization is done on Thing speak, so that record of data can be stored over period of time. This data is stored on web server, so that it can be seen to user who logged into the website using his username and its corresponding password.
\end{abstract}

KEYWORDS: IoT,Arduiuno, Microcontroller,Smart.Health. 


\section{EPRA International Journal of Research and Development (IJRD)}

\section{INTRODUCTION}

Health is the fundamental capability humans require to perceive, feel, and act effectively, as it represents a primary element in the development of the individual. [1] That is why it is necessary to provide adequate ways to manage healthcare by monitoring and medical assistance.[2] Increased life expectancy of the elderly and technological evolution led to innovative and effective solutions for in-home monitoring and treatment of patients.[3] This introduces the use of telemedicine and home monitoring using Internet of Things (IoT).[4] A solution for a sustainable and adaptable patient oriented infrastructure development is presented with the help of Arduino UNO R3.[5] Thus this hopes to achieve a solution that is cheap and economically stable.[6] This proposes architecture for the system, which is developed using the above mentioned devices.[7] The main applications of IoT can be in healthcare, which increase the availability, quality of care and reduces costs. This system will help in real time monitoring of the patient but will be cost.Advancement in information and communication technologies has led to the emergence of Internet of Things.[8] In the contempory health care environment, the usage of IoT technologies brings convenience of physicians and patients, since they are applied to various medical areas (such as real- time monitoring, patient information management, and health care management).[9] The body sensor network (BSN) International Journal of Engineering and Manufacturing Science. technology is one of the core technologies of IoT elaborating in health care system, where a patient can be icient. [10]Thus we can make use of arduino for developing cheap systems in healthcare using IoT.[11]In our system we are measuring patient's parameters like Blood Pressure, temperature, and heart rate sensors. The persons. The doctors, patient or his caretakers are sensors values are collected and the data information is given to arduino and then it is transferred to server.[12][13] The data stored in a database and can be displayed in a website that can be accessed only by authorized given authorization to view the status of the patient. [14][15]

\section{LITERATURE SURVEY}

\subsection{Introduction}

Patient-Monitoring Systems, Reed M. Gardner \& M. Michael Shabot, Year 2014To meet the increasing demands for more acute and intensive care required by patients with complex disorders, new organizational units - the ICUs - were established in hospitals beginning in the 1950s. The earliest units were simply postoperative recovery rooms used for prolonged stays after open-heart surgery. Intensive- care units proliferated rapidly during the late 1960s and 1970s. The types of units include burn, coronary, general surgery, open-heart surgery, pediatric, neonatal, respiratory, and multipurpose medicalsurgical units. Today there are an estimated 75,000 adult, pediatric, and neonatal intensive care beds in the United States.IoT-Based Health Monitoring System for Active and Assisted Living, Ahmed Abdelgawad , School of Engineering and Technology, Central Michigan University, Mt. Pleasant, MI 48859, USA, Year 2017.

[1] The Internet of Things (IoT) platform offers a promising technology to achieve the aforementioned healthcare services, and can further improve the medical service systems IoT wearable platforms can be used to collect the needed information of the user and its ambient environment and communicate such information wirelessly, where it is processed or stored for tracking the history of the user. Such a connectivity with external devices and services will allow for taking preventive measure (e.g., upon foreseeing an upcoming heart stroke) or providing immediate care (e.g., when a user falls down and needs help). Recently, several IoT systems have been developed for IoT healthcare and assisted living applications.

[2] IOT based health monitoring systems , Nayna Gupta \& Sujata Pandey, Year 2012.In this fast pace world, managing work and health simultaneously have become a matter of concern for most of the people. Long waiting hours at the hospitals or ambulatory patient monitoring are well known issues. The issues demands for a health monitoring system which can monitor the daily routine

\subsection{IOT Platform}

\subsubsection{Introduction}

Nowadays, a massive amount of data is being generated and stored in the cloud. One of the main promises of analytics is data reduction with the primary function to support processing with the help of the existing infrastructure. The motivation of this chapter direction comes from data being generated from a variety of sources, such as healthcare industry, communication, messaging networks, mobile sensors and many others, rather than a new storage mechanism. Data reduction techniques for Big Data have three perspectives: descriptive analytics, predictive analytics and prescriptive analytics. In the pay-as-you-go cloud environment, the storage can be very expensive. The perspective of this chapter is represented by: monitoring, analysis 


\section{EPRA International Journal of Research and Development (IJRD) \\ Volume: 5 | Issue: 5 | May 2020 \\ - Peer Reviewed Journal}

and control of environments, based on collected data from a network of sensors. The Internet of Things (IoT) is a paradigm where every object can be identified and has sensing, networking and processing capabilities. The objects can communicate with each other or with other devices or services available over the Internet. Those objects will be ubiquitous and context-aware. The objective of this chapter is to highlight the current status of the evolu- tion, trends and research on Internet of Things applied in e-Health by examine.

The existing system makes use of heart beat sensor to find out the current heart beat level and display it on the LCD screen. The transmitting circuit includes AVR family microcontroller interfaced to LCD screen and this transmitting circuit is powered by $12 \mathrm{~V}$ transformer. Similarly, the receiving circuit includes AVR family microcontroller and RF receiver and also has a $12 \mathrm{~V}$ transformer. The receiver circuit alsoincludes LED light and a buzzer which are used to alert the person supervisingthe heartbeat rate of the patient and turns on the LED light and buzzer as soon as the heartbeat level of the patient does not fall within the normal heart beat level set.

\section{$\square$ Thing Speak}

Internet of Things (IoT) describes an emerging trend where a large number of embedded devices (things) are connected to the Internet. These connected devices communicate with people and other things and often provide sensor data to cloud storage and cloud computing resources where the data is processed and analyzed to gain important insights. Cheap cloud computing power and increased device connectivity is enabling this trend.

IoT solutions are built for many vertical applications such as environmental monitoring and control, health monitoring, vehicle fleet monitoring, industrial monitoring and control, and home automation. At a high level, many IoT systems can be described using the diagram below:

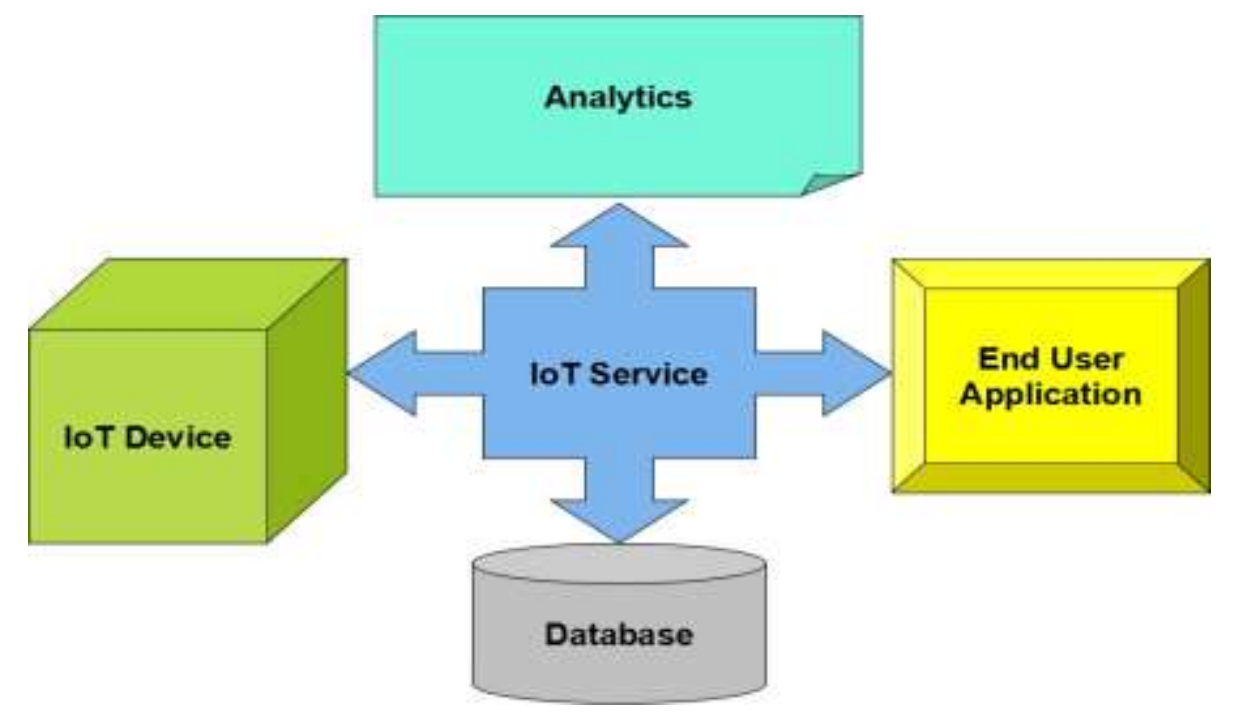

Figure2.1TheFunctionofThingSpeak.

\section{IOT ARCHITECTURE}

The Internet of Things (IoT) is a paradigm where every object can be identified and has sensing, networking and processing capabilities. The objects can communicate with each other or with other devices or services available over the Internet. Those objects will be ubiquitous and context-aware. The objective of this chapter is to highlight the current status of the evolution, trends and research on Internet of Things applied in e-Health by examine. 


\section{EPRA International Journal of Research and Development (IJRD)}

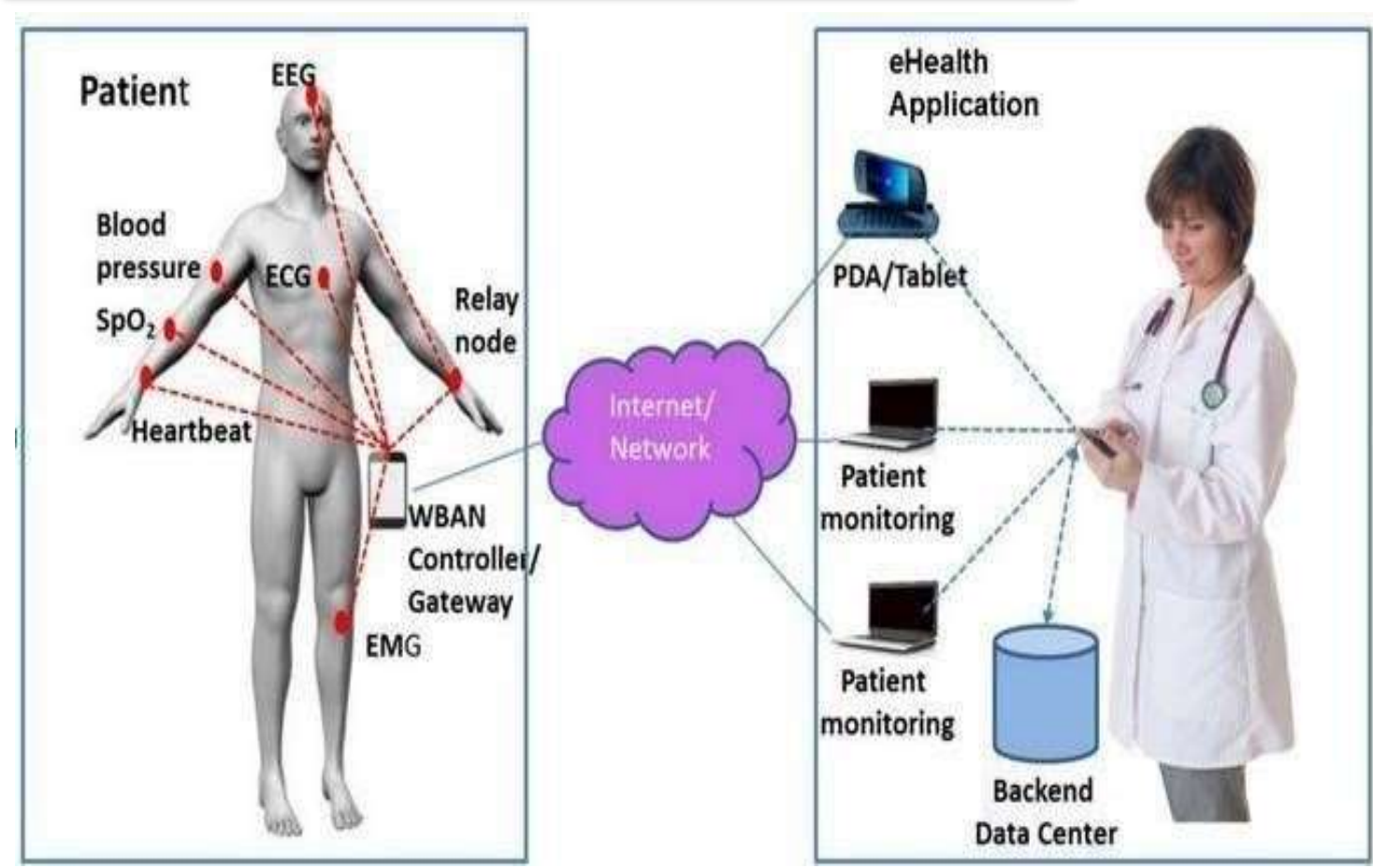

Figure 2.2 Conceptual layout of the ASSET test bed - example of IoT architecture.

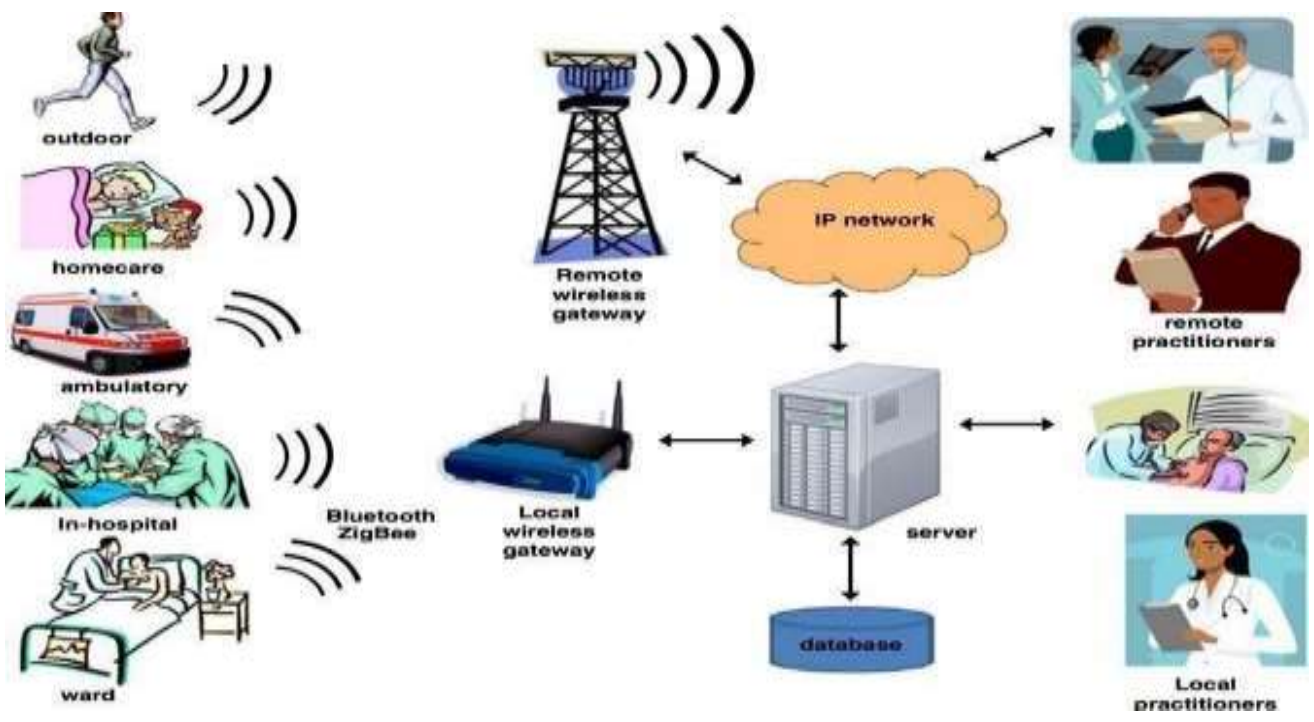

Figure.2.3 Typical architecture of wireless sensor networks in health-care applications.

Based on how the devices are connected to the patient we can classify into:

Implantable

- Wearable

Those devices could be connected on a need basis, always connected or un-Connected.
Based on how the device is connected to the network, the devices can be classified into: wired

- Wireless

- Non-connected

Based on the data generated, the devices can be classified into: 


\section{EPRA International Journal of Research and Development (IJRD)}

Volume: 5 | Issue: 5 | May 2020

- Peer Reviewed Journal

- Real-time streaming (ex. patient monitoring)

- One-time data source (ex. MRI scanner)

- Discrete data sources (oximeter - generates

data at predefined intervals)

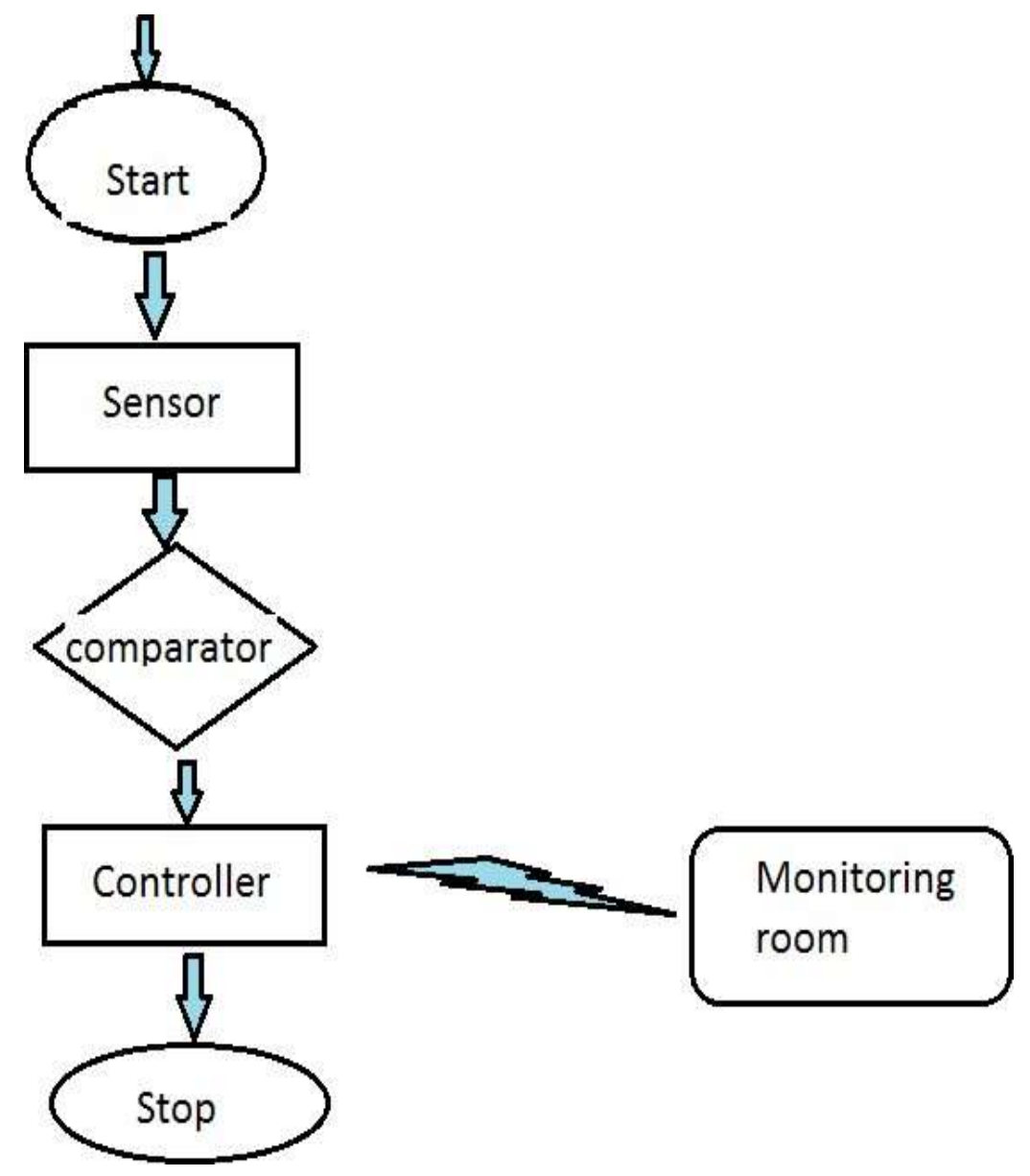

Figure 3.1 Flow Chart Of Proposed System 


\section{EPRA International Journal of Research and Development (IJRD) \\ Volume: 5 | Issue: 5 | May 2020

\section{Block Diagram for Proposed System}

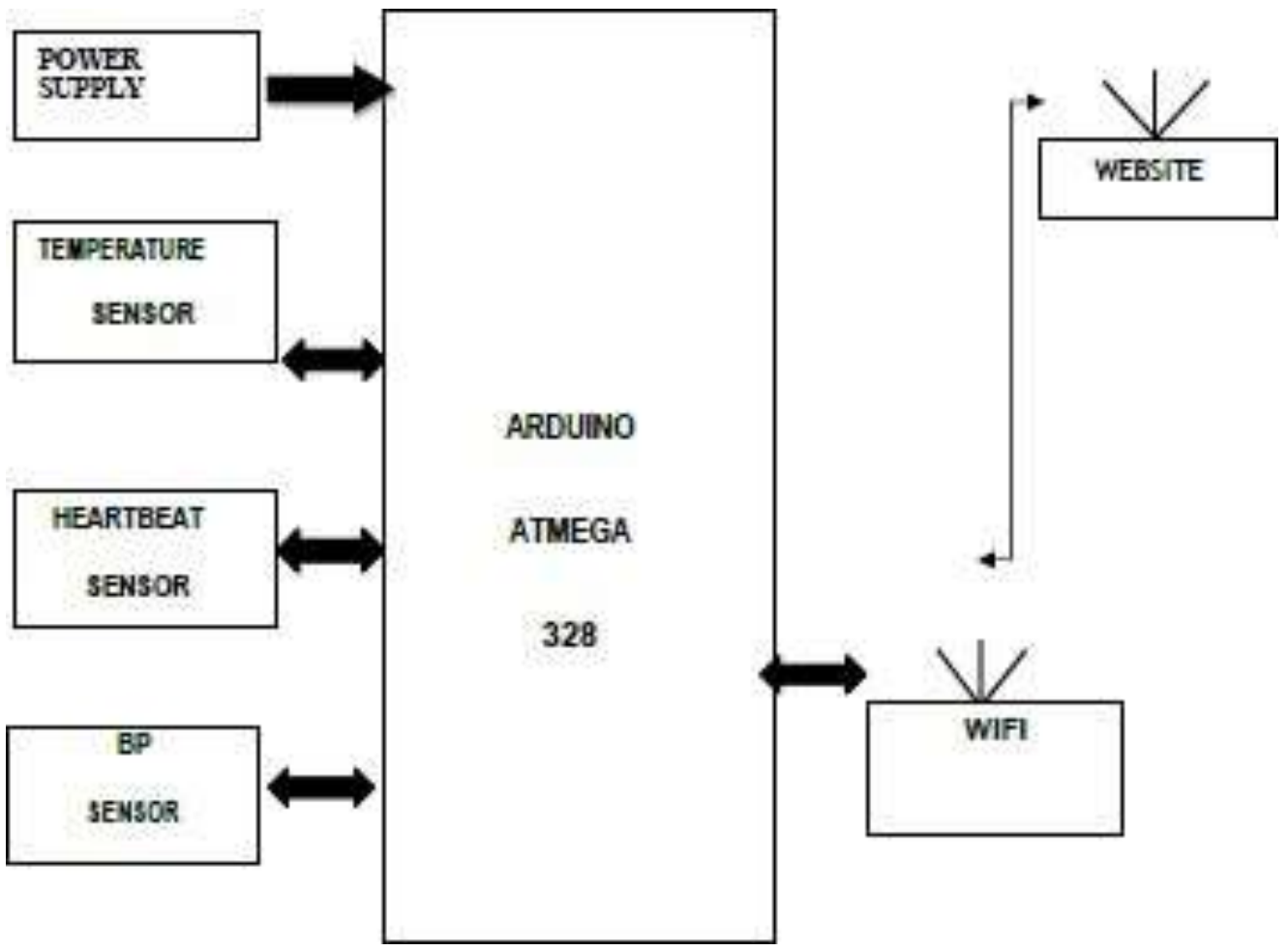

Figure 4.1 Block Diagram for Proposed system

\section{EXPECTED RESULTS}

IOT Monitoring proves really helpful when we need to monitor \& record and keep track of changes in the health parameters of the patient over the period of time. So with the IOT health monitoring, we can have the database of these changes in the health parameters. Doctors can take the reference of these changes or the history of the patient while suggesting the treatment or the medicines to the patient.
Patient health parameter data is stored over the cloud. So it is more beneficial than maintaining the records on printed papers kept in the files. Or even the digital records which are kept in a particular computer or laptop or memory device like pen- drive. Because there are chances that these devices can get corrupt and data might be lost. Whereas, in case of IOT, the cloud storage is more reliable and does have minimal chances of data loss. 


\section{EPRA International Journal of Research and Development (IJRD) \\ Volume: 5 | Issue: 5 | May 2020 \\ - Peer Reviewed Journal}

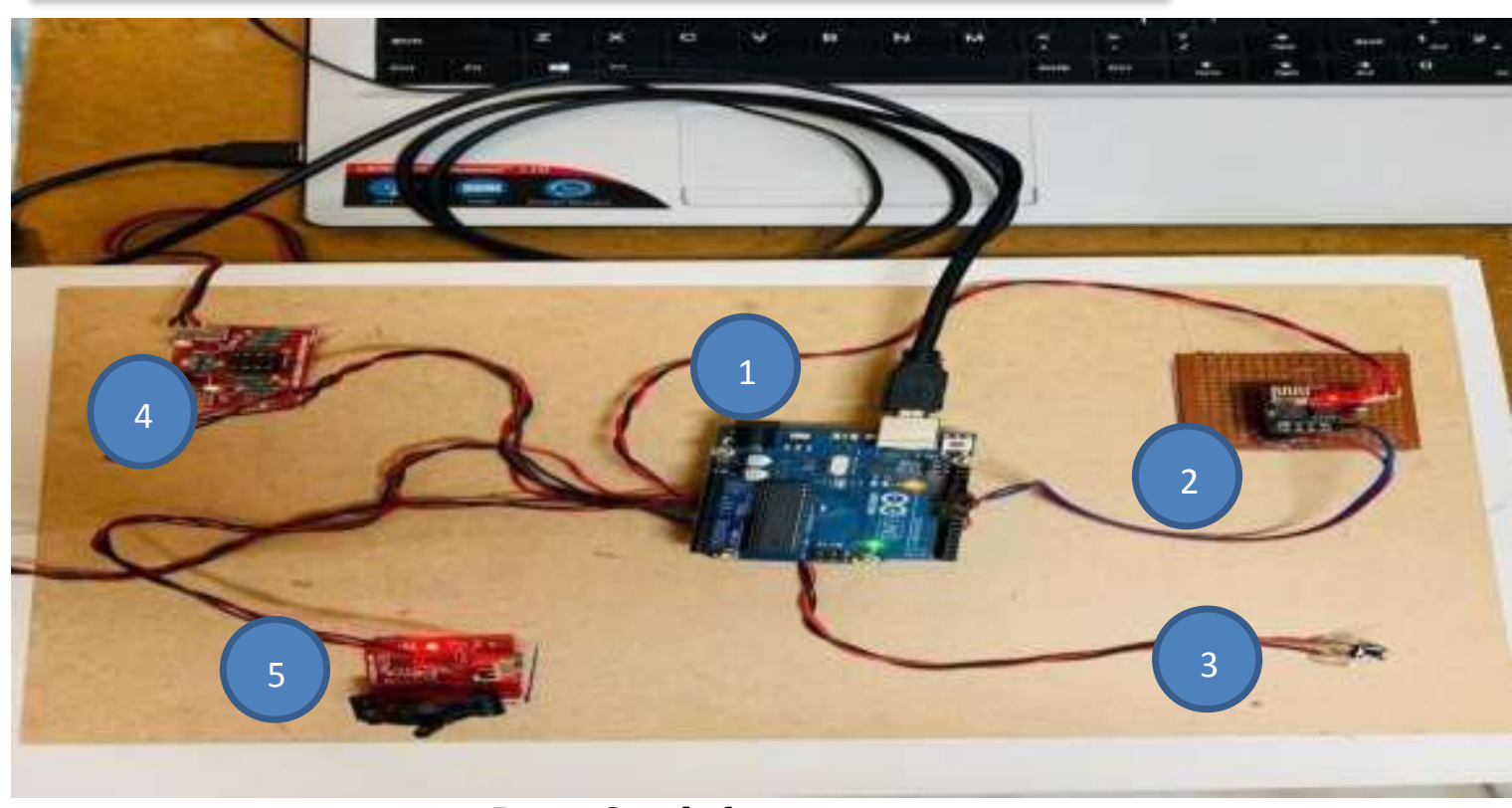

Power Supply from system

Ardiuno board(1) connects couple of sensors together and it provides power for further sensors, here Temperature sensor(3) which give values of patient body temperature, Wifi module(2) which helps to records the values in tremite weblinks. Bloodpressure sensor(5) used to record values of patient's blood pressure levels, Heart rate reading obtained by the HeartBeat Sensor(4), when you place your finger on the sensor. These all sensors and ardiuno has connected to laptop. Values and graphs are observes at tremite and basic LCD of module provided, Working observed in fig 7.1.

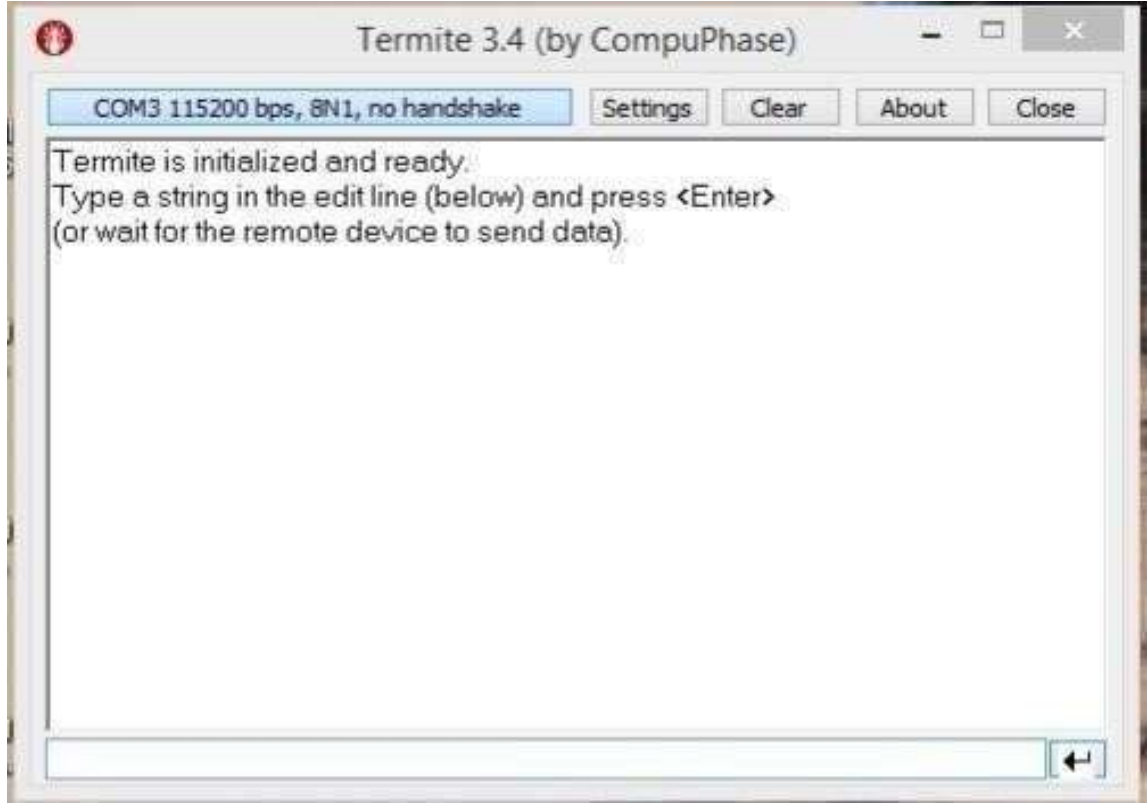




\section{EPRA International Journal of Research and Development (IJRD) \\ Volume: 5 | Issue: 5 | May 2020 \\ - Peer Reviewed Journal}

After checking all the pin connections and adding the library to the Arduino IDE and uploading the source code, run the code. The screen will display the temperature in fahrenheit.

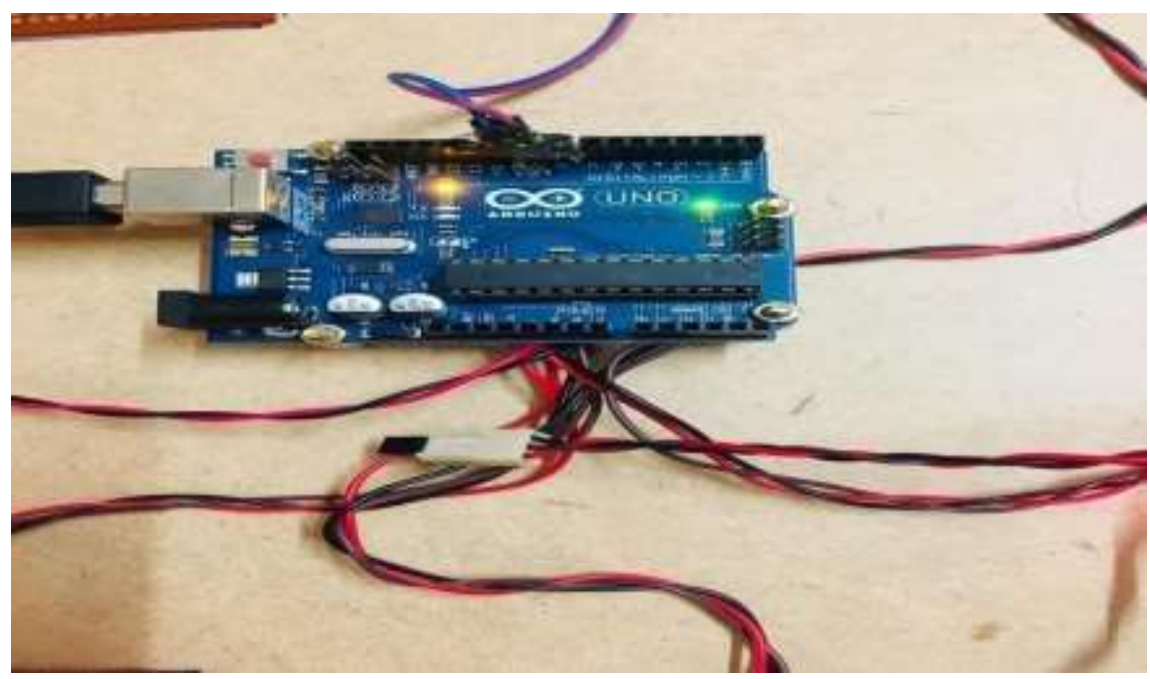

Temperature Sensor

The LM35 series are precision integrated circuit LM35 temperature sensors, whose output voltage is linearly proportional to the temperature in Celsius (Centigrade). The LM35 sensor thus has an advantage over linear temperature sensors, calibrated in ${ }^{\circ}$ Kelvin, as the user is not required to subtract a large constant voltage from its output to obtain convenient centigrade scaling. The LM35's low output impedance, linear output, and precise inherent calibration make interfacing to readout or control circuitry especial.

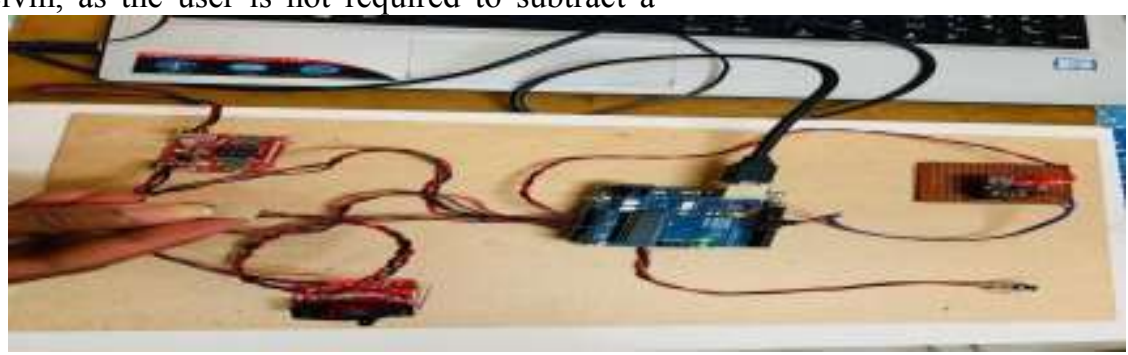




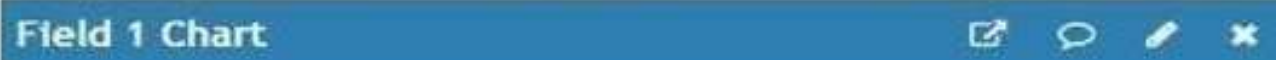

PATIENT HEALTH MONITORING SYSTEM

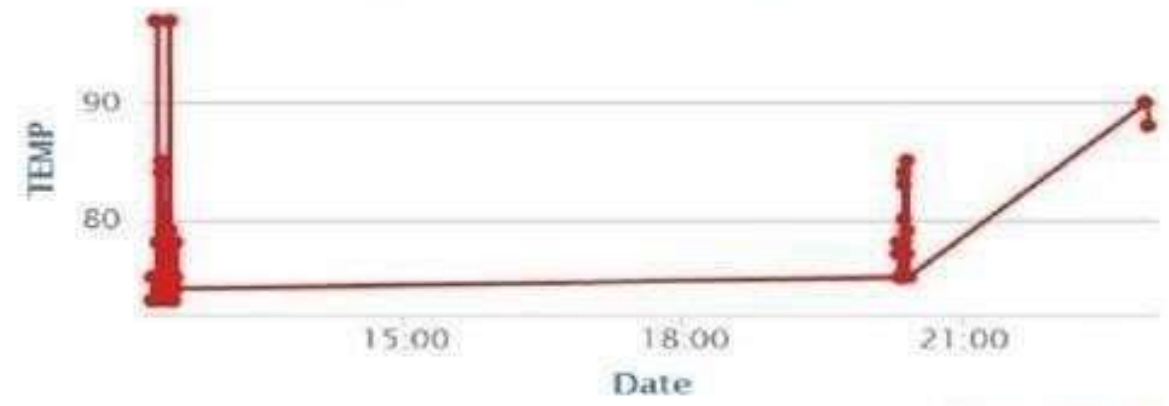

Figure 7.5 Experimental Result Of Temperature Sensor

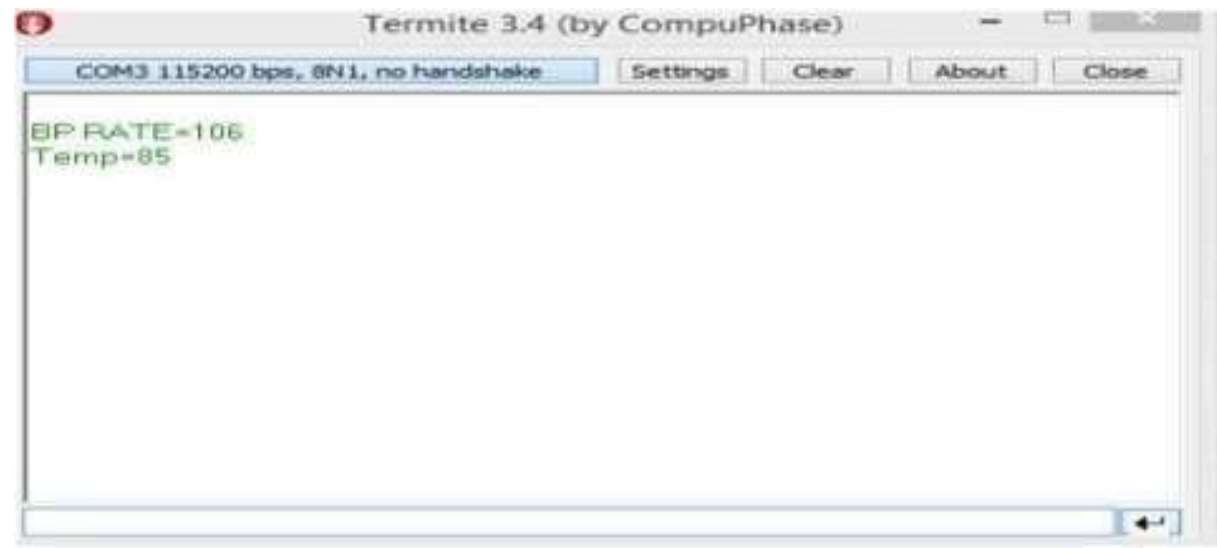

Temperature Result in Termite on system

\section{EXPERIMENTAL RESULTS ON} BLOOD PRESSURESENSOR:

Blood pressure of a person is obtained by Blood Pressure Sensor. When the doctor puts the cuff around your arm and pumps it up, what he/she is doing is cutting off the blood flow with the pressure exerted by the cuff. 


\section{EPRA International Journal of Research and Development (IJRD)}

Volume: 5 | Issue: 5 | May 2020

- Peer Reviewed Journal

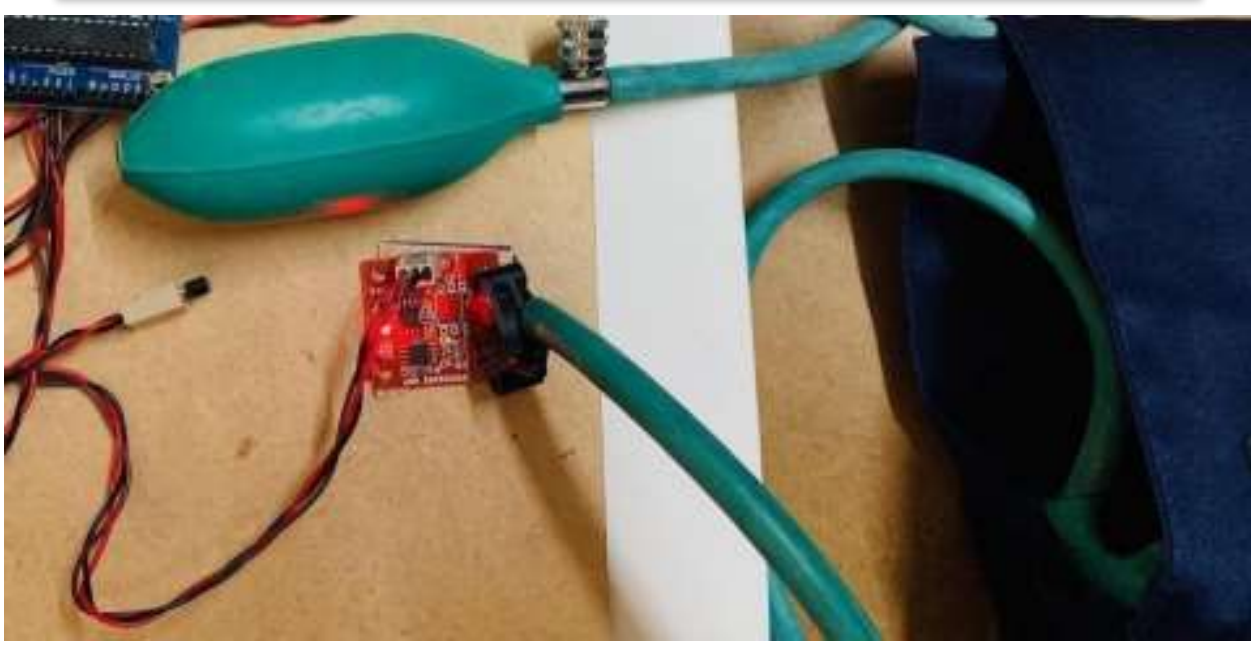

Blood Pressure

Blood pressure measurements were performed before and after the calibrated blood pressure measurements to obtain the systolic and diastolic values of the device designed to be not much different from the analog blood pressure tool, first before calibration and the second after calibration with a 5 minute interval.

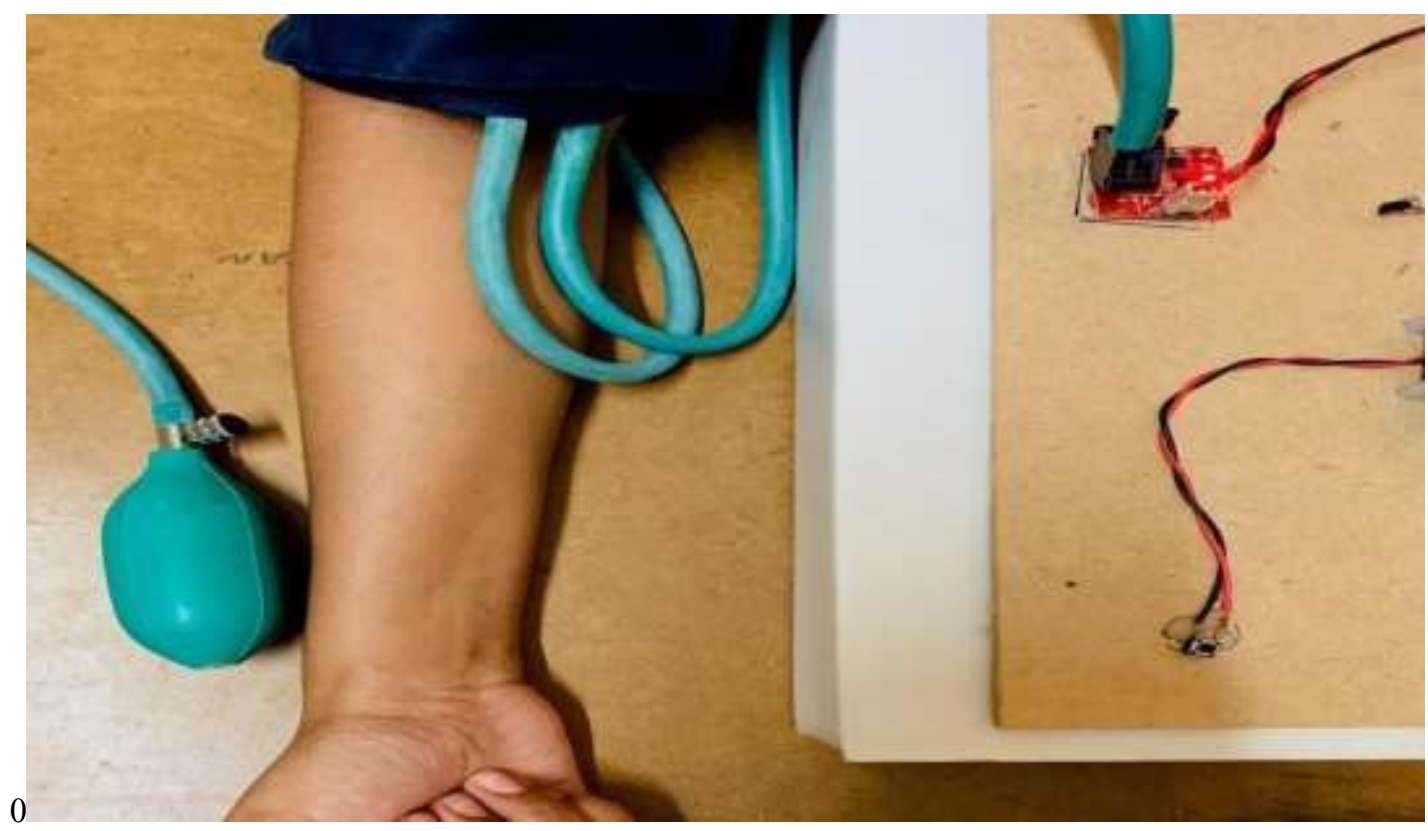

Figure 7.8 Experimentation Of Blood Pressure Sensor

Manually these Blood Pressure sensor connected to ardiuno, its connected to laptop which gives values of regrading patient analysis. It shares the values both in graphical representation and values also In termite web links, it explains at following below fig $7.9 \&$ Fig 7.10 
亩 105

22.57 Date 22.58

Figure 7.9 Experimentation Result Of BP

Figure 7.10 BP Result in Termite on system

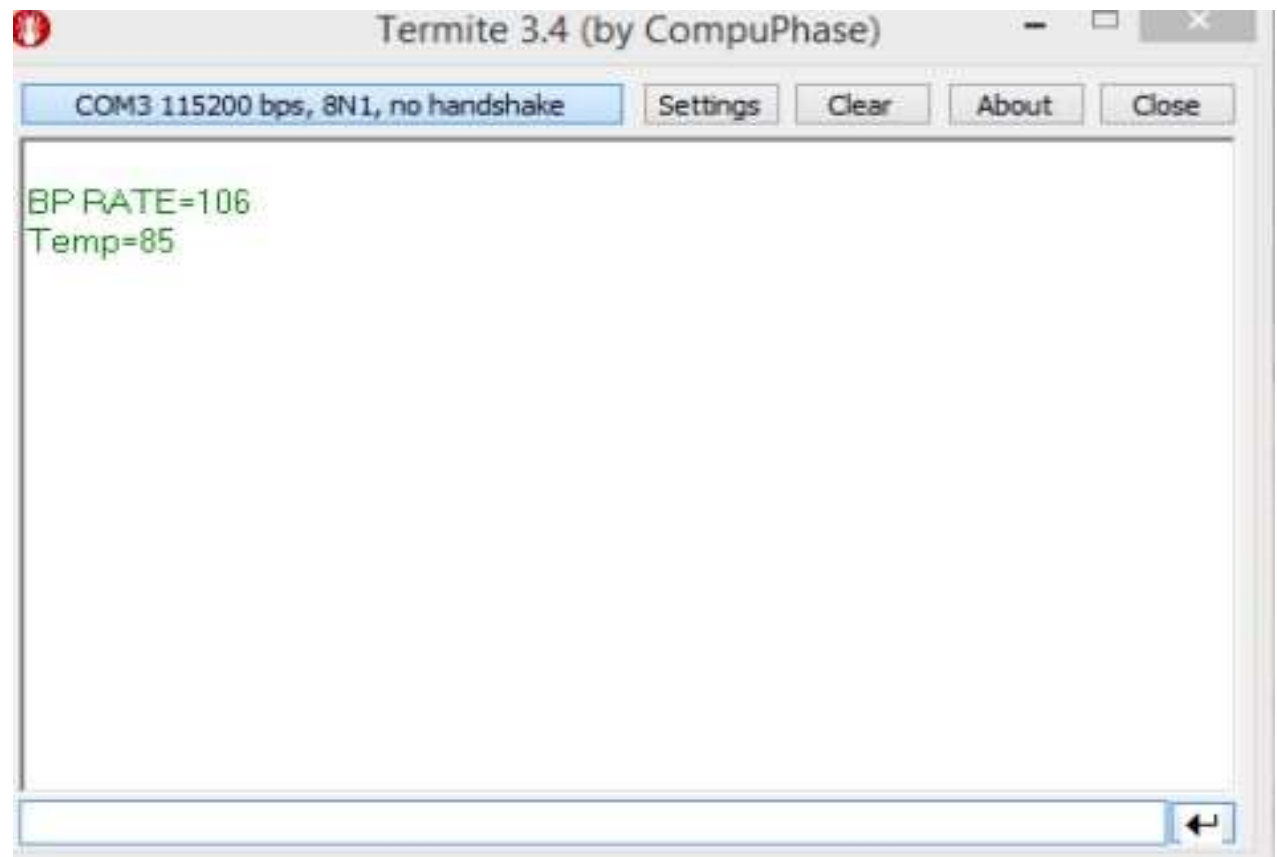




\section{EPRA International Journal of Research and Development (IJRD) \\ Volume: 5 | Issue: 5 | May 2020 \\ - Peer Reviewed Journal}

\subsection{EXPERIMENTAL RESULTS ON HEARTBEATSENSOR:}

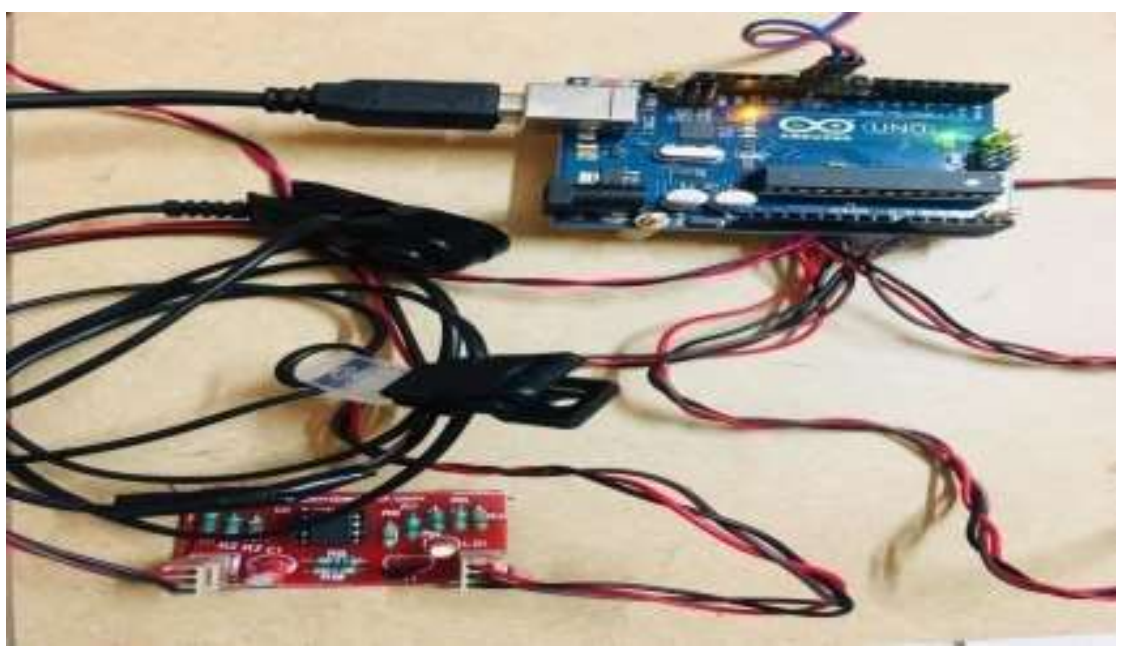

Figure 7.11 Heart beat Sensor

Heart rate reading obtained by the HeartBeat Sensor. Place your index finger on the front side of the pulse sensor, you should see LED1 glow in time with your Human Heartbeat, when you place your finger on the sensor. The heartbeat sensor is based on the principle of photo plethysmography. It measures the change in volume of blood through any organ of the body which causes a change in the light intensity through that organ (a vascular region). In case of applications where heart pulse rate is to be monitored, the timing of the pulses is more important. The flow of blood volume is decided by the rate of heart pulses and since light is absorbed by blood, the signal pulses are equivalent to the heartbeat pulses.

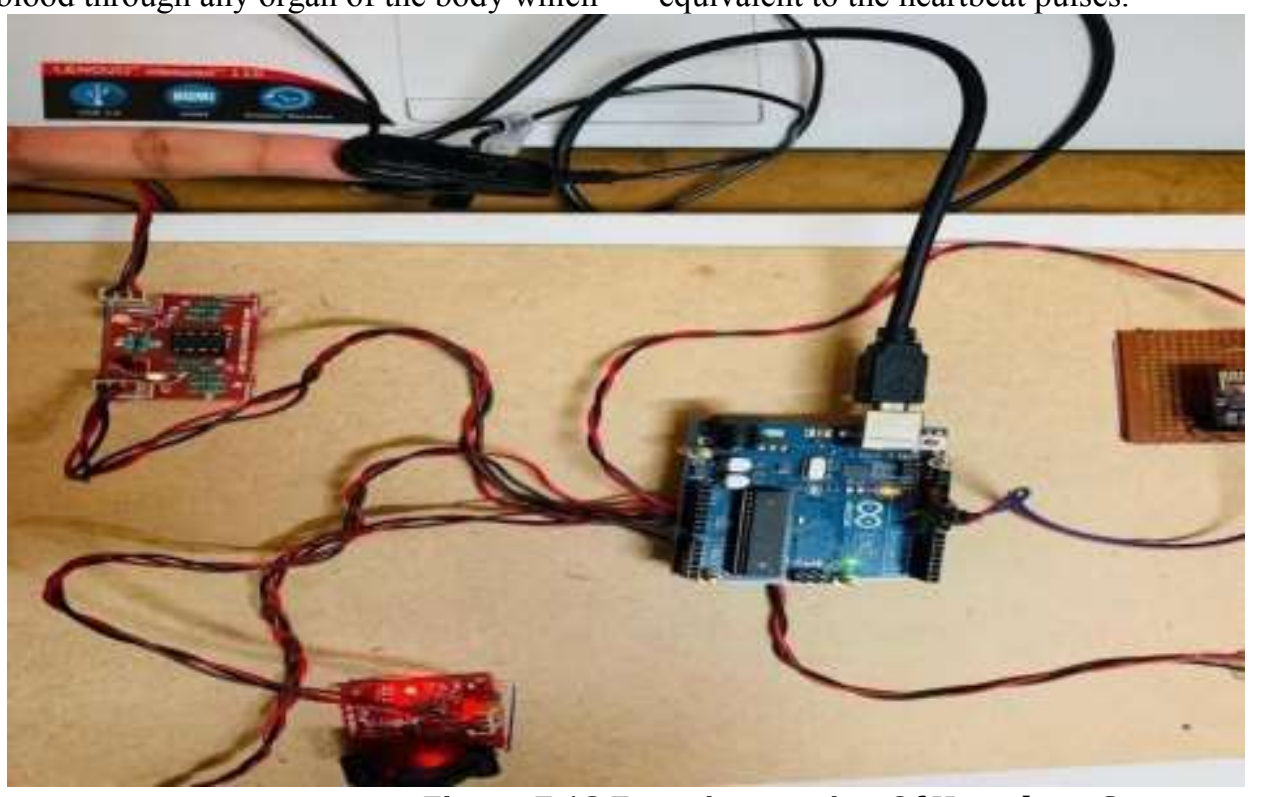

Figure 7.12 Experimentation Of Heartbeat Sensor

Heart rate reading obtained by the HeartBeat Sensor. Place your index finger on the front side of the pulse sensor, you should see LED1 glow in time with your Human Heartbeat, when you place your finger on the sensor.

Manually these heartbeat sensor connected to ardiuno,its connected to laptop which gives values of regrading patient analysis. It shares the values both in graphical representation and values also In termite web links, it explains at following below fig $7.14 \&$ Fig:7.15 


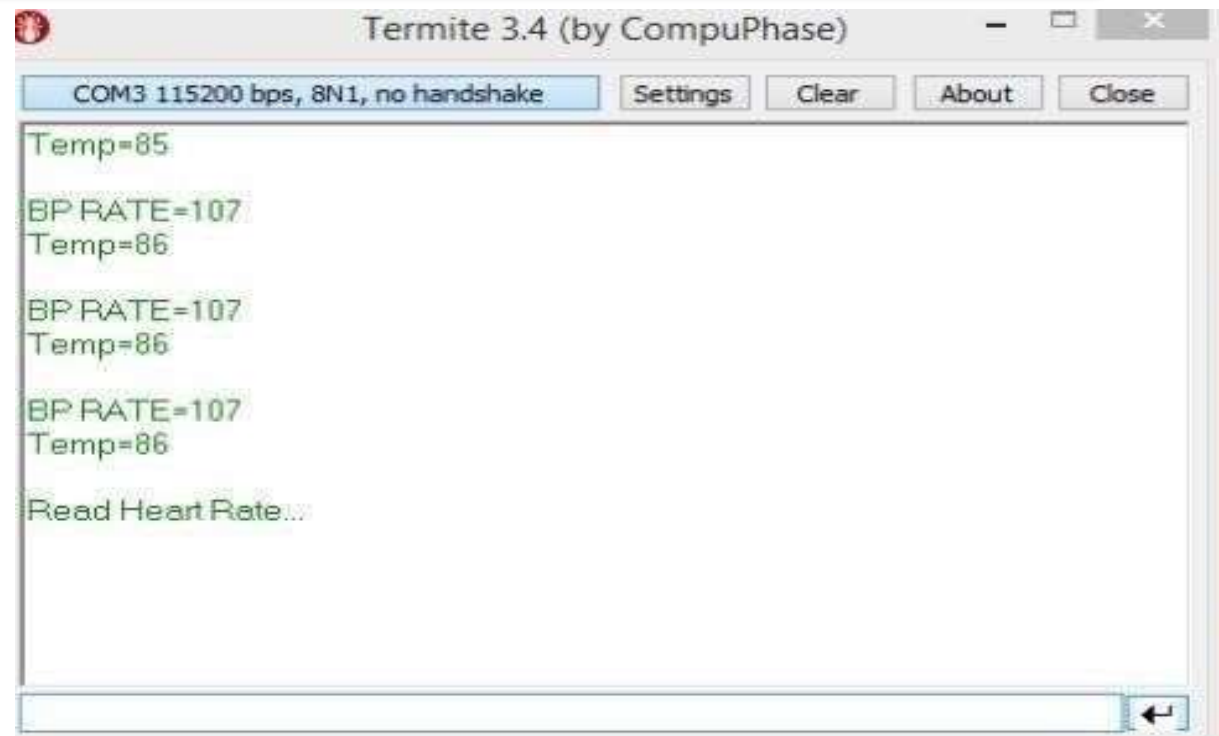

\section{Field 3 Chart $\quad[\odot>x$}

PATIENT HEALTH MONITORING SYSTEM

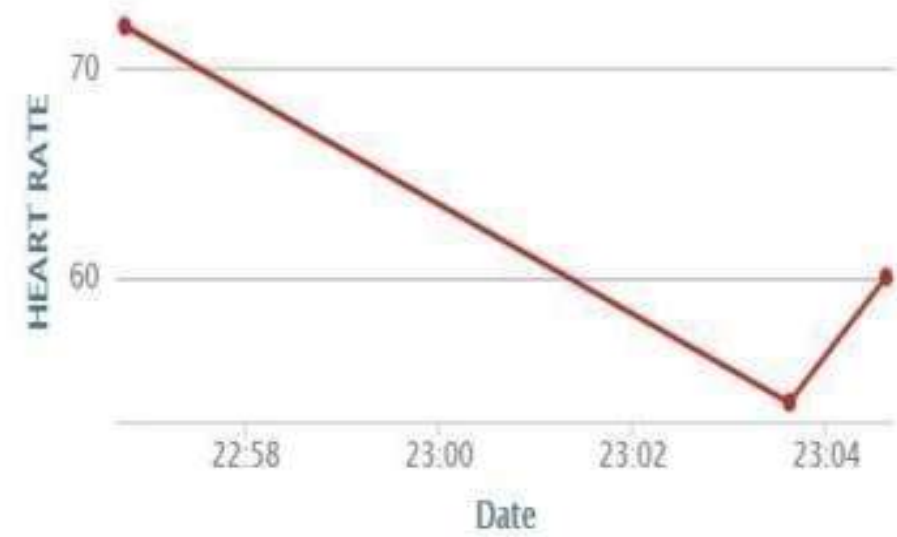

Thingspeak.com

Figure 7.13Experimentation Result Of Heartbeat Sensor 
Figure 7.14 Reading HB in Termite

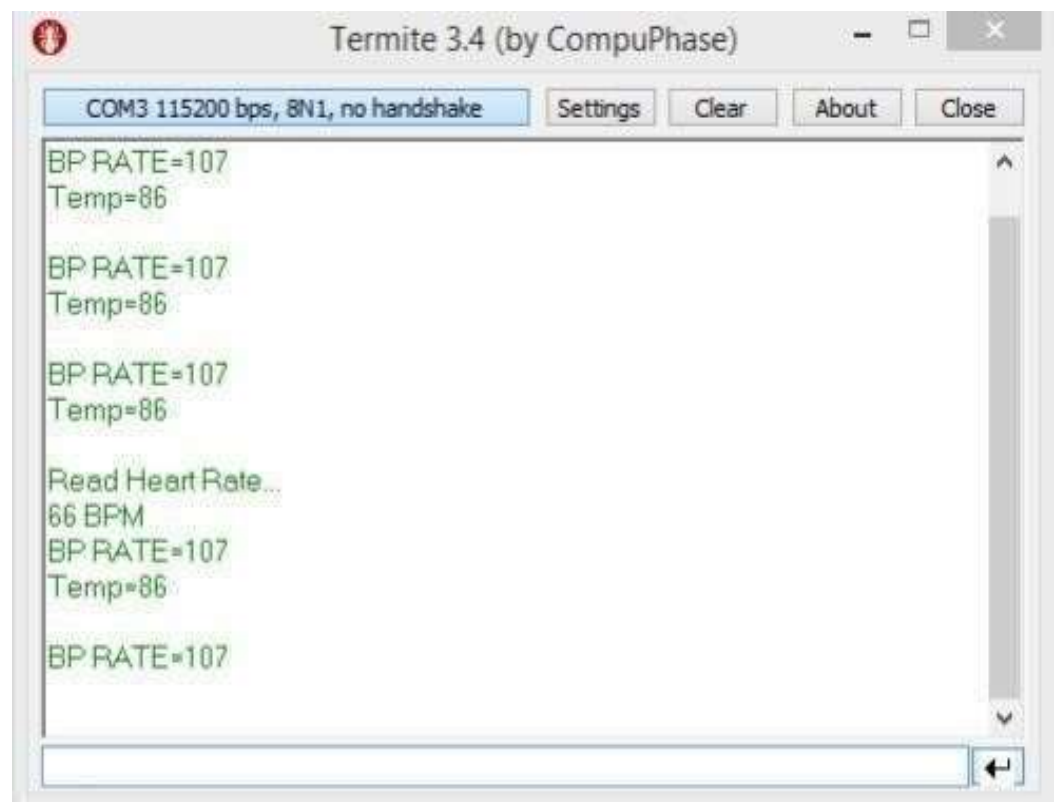

Figure 7.15 HB,BP,TEMP output in Termite on system

\section{CONCLUSION}

Now a days we have an increased risk of health conditions. In general IoT based health care platform which connects with smart sensors attach with human body for health monitoring for daily checkup. In this paper we discussed about IoT based patient health monitoring system. The importance of observing medical patient, continuous remote monitoring is necessary. Our project work is giving the opportunity to monitor patient continuously by using the web along with live monitor service. This system which helps to detect heart rate, blood pressure, temperature of person using heart beat sensing ,blood pressure sensing, temperature sensing even if person is at home. This system also helps for hospital monitoring system, all patient monitored by single person in server room. This system which helps to measure body temperature, heartbeat, pulses of person. so we can save. With online recoding of medical parameters, the workload of the case providers and the nursing staff is reduced.The clinical information database contains all data regarding the patients in electronic form.If this technology will developed then we can detect heart blockage, bradycardia, tachycardia and paralysis ,syncope ,hypertension, hypertensive nethropathy ,hypertensive retinopathy, fever through this technology by our project.

\section{FUTURE ENHANCEMENTS}

In our proposed system we monitor the patient condition especially for the ICU or cardiac patients, hypertension patients. Also we will monitor the whole ward room or patient room from far places by Wi-Fi module.Therefore, person fall detection feature will be added which would be beneficial to older people. But in the future we will upgrade both hardware and software part.In software segment we will upgrade the Website as well as the Apps. We will build a user friendly feature in the website which will show the patient name, date and time description in the ECG segment automatically. Similarly, Apps will be upgraded and uploaded in the Play store. Therefore, people will get the opportunity to download the Apps from Google Play Store and install it in their Mobile phone.

Due to the importance of observing medical state of patients who are suffering from acute diseases, especially cardiovascular diseases, a continuous remote patient monitoring is essential. Internet of Things is able to provide tools to build comprehensive services 


\section{REFERENCES}

1. https://www.irjet.net/archives/V5/i3/IRJETV5I3786.pdf

2. Arduinoarchitecture https://www.engineersgarage.com/embedded/ard uino/getting-started-with-arduino

3. Wireless patient health monitoring system https://ieeexplore.ieee.org/document/6719824

4. Intuitive IoT-based H2U healthcare system for elderly people https://ieeexplore.ieee.org/document/7479018

5. Internet of Thing based healthcare monitoring system https://ieeexplore.ieee.org/document/8079620

6. Internet of things: internet of things, https://en.wikipedia.org/wiki/Internet_of_things.

7. https://www.livescience.com/42081-normalheart-rate.html

8. http://www.instructables.com/id/Pulse-SensorWith-Arduino-Tutorial/

9. http://play.fallows.ca/wp/projects/electronicsprojects/understanding-nodemcu- esp8266-12elimitations

10. Mohammad Wajih Alam1, Tanin Sultana2 and Mohammad Sami Alam3," A Heartbeat and Temperature Measuring System for Remote Human-Health monitoring using Wireless Body Area Network", International Journal of BioScience and Bio- Technology Vol.8, No.1 (2016), pp.171-190.

11. K. Sundara Velrani, Dr.G. Geetha, "Sensor Based Healthcare Information System”, 2016 IEEE International Conference on Technological Innovations in ICT For Agriculture and Rural Development. [12]Heartbeat Monitoring and heart attack detection, Mamidi manisha, Katakan neeraja, International Journal of Innovations in Engineering and Technology(IJIE)

12. R.N. Kirtana, Y.V. Lokeswari, "An IoT Based Remote HRV Monitoring System For Hypertensive Patients".

13. Mallick, Bandana, and Ajit Kumar Patro. "Heart rate monitoring system using finger tip through arduino and processing software." International Journal of ScienceEngineering and Technology Research (IJSETR) 5.1 (2016): 84-89.

14. Gowrishankar, S., M. Y. Prachita, and Arvind Prakash. "IoT based Heart Attack Detection, Heart Rate and Temperature Monitor." 